\title{
DOING AND ALLOWING HARM TO REFUGEES
}

\author{
Bradley Hillier-Smith
}

$\longrightarrow$ THERE ARE CURRENTLY around twenty-six million refugees worldwide who have been displaced from their countries of origin due to war, violence, and systematic human rights violations, and who seek adequate safety and security elsewhere. ${ }^{1}$ Almost unanimously, theorists working on moral obligations to refugees adopt what I term the Duty of Rescue Approach. This approach conceives of Western states as innocent bystanders overlooking the humanitarian crisis of global displacement as it unfolds, and holds that such states have a moral duty to help refugees if they can do so at little cost to themselves. ${ }^{2}$ However, this dominant theoretical approach is limited since it fails to

1 These figures are from UNHCR, "Figures at a Glance." In this paper, I use the term "refugee" in a broader sense than the original definition articulated in UNHCR, The 1951 Convention Relating to the Status of Refugees and Its 1967 Protocol. This definition understands refugees as persons fleeing from persecution specifically. Many theorists criticize this definition as arbitrarily too narrow since it fails to necessarily include persons displaced as a result of war, generalized violence, human rights violations, climate catastrophe, and so on, whom we ought to recognize as legitimate refugees. These theorists therefore advocate a broader definition. See, for example, Shacknove, "Who Is a Refugee?"; Carens, The Ethics of Immigration, 201; Gibney, The Ethics and Politics of Asylum, 6-8; and Miller, Strangers in Our Midst, 79-83. There is a continuous debate on the precise definition, which would be beyond the scope of this paper to enter into. For the purposes of this paper, I will follow David Miller's broad definition of refugees as "people whose human rights cannot be protected except by moving across a border, whether the reason is state persecution, state incapacity or prolonged natural disasters" (Strangers in Our Midst, 83). This captures the variety of causes of displacement and appropriately recognizes the threat to human rights and their protection as a common underpinning of these causes. Accordingly, I understand refugees as persons who have been forced to flee their state of origin owing to the fact that their human rights are under threat or lack protection in that state, and who therefore seek adequate human rights protection elsewhere.

2 See, for example: "Like the bystander we have an unambiguous duty of rescue towards them" (Betts and Collier, Refuge, 99); "If we can provide shelter and safety to refugees without endangering ourselves it would be wrong to turn them away" (Dagger, "Politics, Rights, and the Refugee Problem," 191); “The 'principle of mutual aid' holds that if two strangers meet and one is in need of help, the other person ought to help if the need is urgent and the risks and costs of helping are 'relatively low"' (Walzer, Spheres of Justice, 33); “There is a parallel 
consider certain practices used by Western states in response to refugees that may make us question whether such states are indeed innocent bystanders.

Serena Parekh's The Ethics of Forced Displacement is a notable exception to this dominant approach. Parekh provides a detailed normative analysis of certain harms that refugees endure as a result of Western state practices. ${ }^{3}$ In particular the encampment of refugees - the enclosure of refugees into camps-includes "a sense of captivity as well as the denial of freedom, autonomy and basic human rights ... for prolonged periods of time." ${ }^{4}$ Such camps "rarely uphold the rights that refugees are entitled to, based on the 1951 Convention." Moreover, "because refugees in camps are so vulnerable, basic human rights are routinely violated.... Sexual assault [being] the paradigmatic case."5 Parekh suggests that Western states' seeking to control their borders and admissions has cumulatively resulted in a situation where refugees face the harms of encampment for prolonged periods of time. ${ }^{6}$

This paper builds upon Parekh's significant work, yet differs in important ways. Parekh conceives of the harms that refugees endure as a result of Western state practices as arising from structural processes and thus ought to be understood as a structural injustice. In her own words, "structural injustices are not necessarily the result of deliberate wrongdoing or explicitly unjust policies, but are the unintended outcome of the actions of different agents each working for their own morally acceptable ends." The harmful encampment of refugees is one such structural injustice: "prolonged encampment for example and the violations of dignity and rights that go along with it, is clearly morally wrong, yet it is not the result of deliberate or explicit policy." 8 On this understanding, Western states are not directly harming refugees, nor are they necessarily acting wrongfully. They are instead contributing to structural processes that themselves result

here with the duty of rescue born by individuals in emergencies" (Miller, Strangers in Our Midst, 78); "States have an obligation to assist refugees when the costs of doing so are low" (Gibney, The Ethics and Politics of Asylum, 231). Carens suggests that we have a duty to admit refugees simply because "they have an urgent need for a safe place to live and we are in a position to provide it" (The Ethics of Immigration, 191).

3 James Souter is another important exception. Souter argues that Western states have stringent duties of reparation to refugees whom they have caused to be displaced through military intervention or through supporting repressive regimes; see "Towards a Theory of Asylum as Reparation for Past Injustice," 2.

4 Parekh, Refugees and the Ethics of Forced Displacement, 4-5.

5 Parekh, Refugees and the Ethics of Forced Displacement, 31.

6 Parekh, Refugees and the Ethics of Forced Displacement, 121.

7 Parekh, Refugees and the Ethics of Forced Displacement, 110.

8 Parekh, Refugees and the Ethics of Forced Displacement, 121. 
in the encampment of refugees. Accordingly, Western state obligations to fix such a structural injustice are forward-looking, remedial responsibilities shared among all those whose morally permissible actions nonetheless contribute to constituting and reconstituting the structural processes that cause the injustice. ${ }^{9}$ In this paper, I take a different route by providing a normative analysis not of structural processes but of specific and identifiable state policies and practices that directly affect refugees. There is room then for an exploration of how certain state practices may not constitute structural harms to refugees but direct harms.

The aim of this paper then is to draw attention to and provide a normative evaluation of specific practices used in response to refugee flows by classifying them as either doing or allowing harm to refugees. The Doctrine of Doing and Allowing Harm holds that it is (other things being equal) morally worse and requires a higher level of justification to do harm rather than merely fail to aid and thus allow harm. ${ }^{10}$ Though some philosophers have rejected this doctrine, it remains widely accepted in common morality owing to the widely recognized fundamental and robust moral constraint against harming innocent persons. ${ }^{11}$ I will thus simply assume the doctrine's moral significance in order to reach a normative assessment of state practices that could carry the widespread public agreement necessary to motivate potential reform. If these practices are indeed instances of doing harm, then, contra the dominant Duty of Rescue Approach, states that adopt them are not innocent bystanders, and are not merely failing to aid refugees, but are instead responding to their calls for aid by directly harming them.

To be sure, it is not always impermissible to harm others. ${ }^{12}$ However, such is the strength of the moral presumption against harming innocent persons that the threshold of justification required to make it permissible is substantially high. ${ }^{13}$ Therefore, if it is the case that states are indeed harming innocent ref-

9 Parekh, Refugees and the Ethics of Forced Displacement, 122-25.

10 Woollard, Doing and Allowing Harm, 6-8.

11 For a well-known example, Rachels, in "Active and Passive Euthanasia" rejects the moral significance of the distinction between doing and allowing harm.

12 For example, harming an aggressor in self-defense or other-defense, or convicted criminals through penalties including imprisonment, is generally considered permissible.

There are a few notable cases in moral philosophy in which it might be permissible to harm innocent persons - for example (providing certain conditions are met), in order to save many other innocent people from equal or greater harm (as in certain trolley cases), or to prevent some significantly greater evil or moral catastrophe. Yet it is agreed that the justification for such harm must be substantial. Even act consequentialism (generally considered to be among the more permissive theories) holds that in order for a harm to be permissible it must result in a benefit that is at least as great as the harm caused. 
ugees, then such practices require a particularly substantial justification that will be hard if not impossible to find. If no such substantial justification can be provided, then states that adopt such practices will be committing a significant injustice against refugees.

This can then supplement Parekh's analysis of structural harms. If the state practices considered below harm refugees, they should not be considered structural harms but direct harms, and if these harms cannot be justified they should not be considered a structural injustice but a direct injustice. If they are a direct injustice, then responsible states have (unlike on Parekh's structural model) indeed acted wrongfully and are thereby definitively not innocent bystanders. Such states then will have urgent, decisive, and compulsory duties of justice to refrain from directly harming innocent refugees and to rectify the harm caused, rather than weaker remedial responsibilities to fix a structural injustice to which they have non-wrongfully contributed. Therefore, it is in my view an important task to assess whether certain state practices are directly harming innocent refugees.

\section{ACCOUNTS OF HARM}

To accurately classify state practices as either doing or allowing harm, it is crucial that our background account of the metaphysics of harm can accommodate the distinction. Notoriously, certain common accounts are unable to do so. ${ }^{14}$ Two recent accounts, which are alive to this worry, are suitably formulated to capture the distinction and will therefore provide the necessary background metaphysics. The first is Duncan Purves's Revised Counterfactual Account:

Harming as Making: An event $E$ is a harm for $S$ if and only if (1) $E$ makes $S$ (as opposed to allows $S$ to) occupy $S$ 's well-being level in the $E$-world (the world in which $E$ does occur), and (2) $S$ 's well-being level is higher in the nearest possible world in which $E$ does not occur.

Agential Harming as Making: An agent $X$ harms a subject $S$ qua agent just in case there is some event $E$ such that $E$ is a harm for $S$ and $E$ is an action (behavior) performed by $X .^{15}$

On this account, Alice harms Brian by punching him, since punching him is an action (behavior) performed by Alice that makes Brian (rather than allows Bri-

14 For example, consider the basic formulation of the counterfactual comparison account discussed in Hanser, "Harm."

These definitions are adapted from Purves, "Harming as Making Worse Off," 2643-44. 
an to) occupy a certain level of well-being that is lower than it would be in the nearest possible world where the punch did not occur. Carl's failure to prevent Alice's punch would not count as a harm, since this is not an action (behavior) performed by Carl, and did not make the harm occur, but rather merely allowed it to occur.

The second is Molly Gardner's Existence Account:

Harming (def): An event $E$ harms an individual $S$ if and only if $E$ causes (rather than allows) a state of affairs that is a harm for $S$.

Harm (def): A state of affairs $T$ is a harm for an individual $S$ if and only if (1) there is an essential component of $T$ that is a condition with respect to which $S$ can be intrinsically better or worse off, and (2) if $S$ existed and $T$ has not obtained, then $S$ would be better off with respect to that condition. ${ }^{16}$

This account focuses on, first, whether an event causes (rather than allows) a certain state of affairs and, second, whether that state of affairs is itself harmful for a person. A state of affairs that could be harmful for a person would be one where that state of affairs meant that an aspect of their well-being (physical pain, mental distress, personal autonomy, and so on) is intrinsically worse than it would have been had that state of affairs not obtained. On this account, Alice harms Brian by hitting him with her fist since this causes a state of affairs that is a harm for Brian: being punched. This is a harmful state of affairs because a component of being punched, enduring some pain or injury, is a condition with respect to which Brian could be better or worse off, and if Brian had existed and that state of affairs had not obtained (Brian had not been punched), then Brian would have been better off in that regard. Carl's failure to prevent the punch would not count as a harm since it did not cause the harmful state of affairs but rather merely allowed the harmful state of affairs to occur.

Following these accounts, a state practice will count as harming refugees if either it makes refugees (rather than allows them to) occupy a level of well-being that is worse than it would be in the nearest possible world in which that practice does not occur (Revised Counterfactual Account), or causes (rather than allows) a state of affairs that is itself a harm for refugees in that an essential component of that state of affairs is a condition with respect to which refugees can be intrinsically better or worse off, and if the refugees existed and that state of affairs had 
not obtained then refugees would be better off with respect to that condition (Existence Account). What must be established then is whether state practices count as making or causing these harms or not: Are they doing or allowing harm to refugees?

\section{CLASSIFYING STATE PRACTICES}

Let us now consider particular practices that certain states have adopted in response to refugees seeking safety.

\subsection{Border Violence}

In Calais, France, numerous instances of violence and human rights abuses by UK-funded Compagnies Républicaines de Sécurité (CRS) riot police have occurred at the border. ${ }^{17}$ The CRS can use extreme violence in forced evictions of camps where they use beatings with batons, water cannons, tear gas, and rubber bullets, including against children. ${ }^{18}$ Such tactics can cause severe injury. The CRS also roams the area and reportedly uses pepper spray and tear gas in unprovoked attacks, often while refugees are sleeping in makeshift shelters. ${ }^{19}$ As witnessed myself when volunteering in Calais, in some cases police will confiscate just one shoe from refugees in an attempt to humiliate them as they walk around with a limp.

At the Hungarian border with Serbia, there have been violent pushbacks of refugees. Police reportedly beat refugees for hours on end, causing serious and life-changing injuries; some then take selfies with the injured persons. They reportedly confiscate warm clothing and douse refugees in water during freezing temperatures, increasing hypothermia risk. ${ }^{20}$

These examples are part of a larger trend of "crackdowns" of refugees with further similar instances of violence and human rights abuses against refugees at Croatian, Slovenian, Greek, and Italian borders, with children at particular risk of abuse. ${ }^{21}$

17 See Human Rights Watch, "France” and "Like Living in Hell”; L'Auberge des Migrants, Calais. See also Hiller-Smith, "The Situation on the English Channel Is Indeed a 'Major Incident.”

18 Quine, "Calais Jungle Refugees Have Sewn Their Mouths Shut in Protest at the Camp Clearance."

19 Dutton, "For Refugees in Calais, Police Brutality Is a Daily Occurrence."

20 Dearden, "Hungarian Border Guards 'Taking Selfies with Beaten Migrants”; Human Rights Watch, "World Report 2018."

21 Amnesty International, "Croatia”; Save the Children International, "Hundreds of Children Report Police Violence at EU Borders.” 
Border violence is straightforwardly harming refugees. Severe beatings, tear gas, water cannons, and rubber bullets used during evictions and pushbacks, as well as tactics of intimidation, humiliation, and other human rights abuses undeniably cause direct physical suffering, injury, and mental distress, and make refugees worse off in these aspects of their well-being than they would have been had such acts not occurred and those resultant states of affairs not obtained. No further analysis of border violence is required to classify it as either doing or allowing harm. States that engage in border violence are not innocent bystanders but are harming refugees.

\subsection{Detention}

In an arrangement between European Union (EU) member states and Libya, refugees attempting to find safety in Europe are returned to indefinite and arbitrary detention in appalling conditions in centers on the Libyan coast (that are funded by EU states including the UK). ${ }^{22}$ Overcrowding and lack of sanitation have led to starvation, disease (in particular tuberculosis), and death. Refugees, including children, face grievous maltreatment in the centers: being raped, beaten, abused, starved, and even traded as slaves. ${ }^{23}$ Documented footage depicts the torture, showing refugees being burned, maimed, and electrocuted. ${ }^{24}$ A Somali man recently self-immolated and died of his wounds in protest against his incarceration, maltreatment, and conditions in the Triq al Sikka detention center. ${ }^{25}$ This is a testament to how unimaginably unbearable and hopeless conditions can be. Had he not been detained, this man was eligible for asylum in the $\mathrm{EU}$, including the UK.

Detention is an instance of doing harm. Without the forced detention, such refugees were eligible and thus would have claimed and likely been granted asylum in EU states. Placing refugees in these detention centers therefore makes refugees worse off in aspects of their well-being (physical and mental health, subsistence, liberty, physical security, including freedom from rape and torture) and causes them to be in an undeniably harmful state of affairs where such aforementioned aspects of their well-being are worse than they would have been had such detention not obtained.

It might be objected that EU states did not cause the harmful conditions in the detention centers but merely put refugees in those conditions and allowed

Human Rights Watch, "Towards an Effective and Principled Eu Migration Policy”; and Taylor, "Libya."

23 BвC News, "Migrant Slavery in Libya."

24 Footage is from Channel 4 News, "EU Immigration."

25 Hayden, "Somali Returned to Libya under Italian Policy Sets Himself on Fire." 
such harms to occur. However, even if one did not initiate a potentially harmful sequence but merely placed a person in its path, this does not constitute simply allowing harm. On the contrary, knowingly putting someone in harm's way (or a condition where harm will occur to them) constitutes doing harm. If I push you off the platform into the path of an oncoming train that then hits you, I have quite clearly harmed you, even if I am not responsible for the fact that the train was in motion. Few would deny that an agent's placing someone into a fire, or throwing them into a lake where they may drown, or throwing them to the lions are acts of doing harm even if the agent does not cause the harmful conditions into which they place their victim. Putting a person in harm's way, in this case putting refugees in conditions where they will suffer disease and severe human rights violations, is a harm. Forced detention harms refugees. This fact is as inescapable as the detention itself. Therefore, states that adopt the detention of those seeking safety are not innocent bystanders but are harming refugees.

\subsection{Encampment}

As part of an EU-Turkey deal to stem refugee flows entering Europe, refugees who made the dangerous sea crossing from Turkey are forcibly enclosed in squalid camps on the Greek Islands. ${ }^{26}$ This encampment of refugees into conditions without adequate basic supplies of food, shelter, sanitation, and medicine, and where they face extensive human rights violations (in particular pervasive sexual violence), has "caused immense suffering for asylum seekers." ${ }^{27}$ In the Moria camp, for example, where 3,000 children are among those encamped, "the sewage system is so overwhelmed, that raw sewage has been known to reach the mattresses where children sleep." 28 There is also a significant threat of physical violence, including the gang rape of women, and children being subjected to sexual violence. ${ }^{29}$ The mental toll caused by encampment is significant such that "many people have attempted to end their lives due to the extreme distress and emotional pain they experience." 30

This example of encampment is different from those considered by Parekh since it is the direct result of a specific policy. And, just as with detention, this encampment is an instance of directly doing harm to refugees. Forcing refugees into squalid camps makes it the case that refugees are, and causes them to be, confined into enclosed spaces where aspects of their well-being (free movement,

26 Human Rights Watch, "Q\&A."

27 Human Rights Watch, "Q\&A."

28 International Rescue Committee, "Unprotected, Unsupported, Uncertain."

29 Human Rights Watch, "Why Greece Should \#OpenTheIslands."

30 See Tondo, “We Have Found Hell." 
liberty, mental and physical health, subsistence, freedom from sexual violence) are worse off than they would be they not been placed in these camps and that state of affairs had not obtained. States that forcibly encamp refugees are not innocent.

\subsection{Containment}

The arrangement with Libya also blocks refugees from traveling from Libya to the EU where they could otherwise have claimed asylum and found adequate safety. It thereby closes off the main migratory route from North Africa to Europe and so contains refugees in harmful conditions in regions in North Africa where their basic subsistence and security needs are not met, and where they are subjected to extensive human rights violations. ${ }^{31}$

Similarly, the EU-Turkey Deal blocks refugees from traveling to Greece from Turkey and so this main migratory route to safety in Europe is also closed down. Refugees are thereby contained in regions nearer their countries of origin in Turkey, Jordan, and Lebanon to reside in squalid camps and face destitution in urban areas where they endure extreme poverty and extensive human rights violations (in particular, sexual violence). ${ }^{32}$

The explicit purpose of containment policies such as those above is precisely that: to contain refugees in certain regions by blocking off migratory routes to seek safety in Western states. The direct result of these policies is that refugees are contained in regions where they then face extreme poverty and extensive human rights violations. It is difficult to classify this as either doing or allowing harm. On first assessment, it appears to be doing harm. Blocking off escape routes to safety makes it the case that refugees are (and causes them to be) confined in these otherwise avoidable harmful conditions where aspects of their well-being are worse than they would otherwise have been. In the absence of containment, refugees would not have been entrapped in these conditions (that harmful state of affairs would not have obtained) and would instead have been able to travel to find safety in Europe. On the other hand, containment could be said to merely allow harm. Containment policies do not cause the harms (the extreme poverty and extensive human rights violations) that refugees endure in regions close to their countries of origin, nor do they actively place refugees into these conditions (as they do in cases of detention and encampment); they

31 UNHCR, "North Africa."

32 Human Rights Watch, "Q\&A"; UnHCR, Global Trends, 55, and "UNHCR Study Shows Rapid Deterioration in Living Conditions of Syrian Refugees in Jordan"; Chatty, “The Syrian Humanitarian Disaster"; un News Service Section, "Conditions of Syrian Refugees in Lebanon Worsen Considerably, un Reports." 
merely allow such already existing harms to occur. Due to this indeterminacy, containment requires closer analysis.

\section{CONTAINMENT AS A SAFETY-NET CASE}

The literature on so-called Safety-Net Cases, which are also difficult to classify, may be useful here. In Safety-Net Cases, an agent acts to remove an obstacle that would have prevented harm to a victim, and as a result of this action the victim is harmed. Consider the following examples:

Hospital: A doctor has just plugged one person into a respirator. If the patient is moved or unplugged from the respirator, he will die. Five more patients arrive and will die unless plugged into the respirator. The doctor unplugs the first patient into order to save the five. ${ }^{33}$

Burning Building (Enemy): A person trapped atop a high burning building leaps off. Seeing this, a firefighter quickly stations a self-standing net underneath and then dashes off to assist with other work. The imperiled person's enemy, however, is also present and, seeing his opportunity, swiftly removes the net so the imperiled person hits the ground and dies. ${ }^{34}$

Are these cases of removing the safety net doing or allowing harm? Intuitively Hospital strikes us as allowing harm where Burning Building (Enemy) strikes us as doing harm. How do we explain these divergent judgments? Jeff McMahan provides a rationale: removing a safety net counts as allowing harm if and only if the safety net was provided by the agent and the safety net was either not self-sustaining or not yet operative. ${ }^{35}$ Therefore, since the doctor provided the respirator and it was not self-sustaining (it required continued maintenance and monitoring), this removal counts as allowing harm. The enemy, on the other hand, removed a self-sustaining safety net that was not provided by him, so this counts as doing harm.

Fiona Woollard largely agrees, yet refines McMahan's analysis to yield the following. An agent removing a safety net will count as doing harm

if and only if (a) the [net] does not require the continued use of resources belonging to the agent and either (b) the [net] is owned by the victim or by a third party who has given, or would give, valid authorization for the victim to use the [net] or (c) the victim has a non-need based claim to the

33 Rickless, "The Moral Status of Enabling Harm.”

34 McMahan, "Killing, Letting Die, and Withdrawing Aid."

35 McMahan, "Killing, Letting Die, and Withdrawing Aid." 
use of the [net] that is stronger than any non-need based claim the agent has to the $[$ net $] .^{36}$

The respirator was owned by the doctor (or he had valid authorization for its use) and it required his continued monitoring and maintenance, so this counts as allowing harm. The enemy, on the other hand, did not own the net and it was self-sustaining in that it did not require continued resources to be operative. Therefore, the (henceforth) McMahan-Woollard classification adequately captures and convincingly explains strong intuitive judgments in the above cases and thus represents a plausible account of classifying Safety-Net Cases.

Can containment then be conceived of as a Safety-Net Case to which we could apply the McMahan-Woollard classification? It may initially appear so: there is a potentially harmful sequence in motion that will result in harm to refugees (they are facing extreme poverty and extensive human rights violations). Fortunately, there is a safety net: a safe state's territory. Such states then act to remove this safety net and thus harm occurs to refugees.

However, this framing of containment is not quite accurate. A Safety-Net Case is one where an agent acts to remove an object that would have prevented a harmful sequence. Containment policies are subtly but importantly different. In initiating a containment policy to block a migratory route to safety, an agent acts to place, introduce, or create a new object that blocks an escape from a harmful sequence. As such this cannot count as a Safety-Net Case. Instead, I propose a different approach to understand containment that recognizes its distinction from Safety-Net Cases. To help see the difference, consider the following cases:

Removing the Safety Net: There is a person at the foot of a hill. A boulder is rolling down the hill, but there is an obstacle in its path that will halt the boulder. An agent acts to remove the obstacle. Now the boulder rolls the full way down to kill the person below.

Denying the Escape: A boulder is rolling down the hill uninhibited toward a person, where it will kill him. Yet the imperiled person can simply step aside from the boulder's path such that it will roll by. An agent acts to place an obstacle in the way that prevents the victim from stepping aside, thus the boulder kills him.

In Removing the Safety Net, an agent acts to remove an object that already exists within a sequence of events that would prevent a harm. In Denying the Escape, an agent instead acts to place, introduce, or create a new object into a sequence of events that prevents an escape, thus ensuring that the harm occurs. Denying

36 Woollard, Doing and Allowing Harm, 81. 
the Escape is subtly but importantly different from Safety-Net Cases. It therefore belongs to a different category of cases that to my knowledge has not been sufficiently considered in the literature on doing or allowing harm. ${ }^{37} \mathrm{I}$ shall term such cases Denial of Escape Cases.

For a case to count as a Denial of Escape it must be the case that (1) there is a preexisting, potentially harmful sequence of events in motion that threatens a victim, (2) there is a preexisting means of escaping that sequence for the victim to avoid harm, (3) an agent acts to place, introduce, or create an obstacle to block that means of escape such that (4) the placing, introducing, or creating of the obstacle makes it the case that the potentially harmful sequence of events does in fact harm the victim.

Containment is a Denial of Escape Case. There is a potentially harmful sequence in motion: refugees are in harm's way, facing extreme poverty and human rights violations. Fortunately, they can escape by seeking safety in another state. States nonetheless act to put an obstacle in the way (a containment policy) that prevents them from escaping and thus ensuring that harm will come to refugees as they are made to endure the extreme poverty and human rights violations. This description of containment as a Denial of Escape Case more accurately captures the relevant facts compared to understanding containment as a Safety-Net Case, since it recognizes the crucial facts that state(s) introduce a new object (a containment policy) that blocks an escape from a harmful sequence.

\section{IS DENIAL OF ESCAPE DOING OR ALLOWING HARM?}

To assess whether Denial of Escape is doing or allowing harm, let us first compare intuitive judgments across cases. Consider the following standard doing-harm case:

To be clear, we are considering cases of whether denying a person's escape from a harmful sequence constitutes doing or allowing harm. I thank an anonymous reviewer for enjoining me to further consult the literature on doing and allowing to see whether such cases have been explicitly articulated and analyzed. In such a consultation I did not come across such cases being discussed. Indeed, in private correspondence with Fiona Woollard, whose research on Doing and Allowing Cases is formidable, she agreed that such a case was seemingly new to her. However, more recently, I have come across such cases being discussed in the literature on defensive harm. Yet, the discussion in this literature concerns whether it is permissible or not to kill an agent who blocks one's escape from a threat. It does not, to my knowledge, discuss or seek to establish whether placing an obstacle to block an escape is itself doing or allowing harm; see for example Frowe, Defensive Killing, 24-26. Therefore, I believe that there is room to explore the classification of Denial of Escape Cases as either doing or allowing harm. 
Push: A train is coming along the tracks, where it will pass by. You push an innocent stranger into the path of the train and the stranger is killed.

Push is undeniably doing harm and (if perpetrated for no good reason) is a paradigm case of the morally outrageous. Importantly, note that to count as doing harm it does not matter that you did not initiate the train in motion. What matters is that you act to interfere in the sequence of events to ensure the stranger is in its path when she otherwise would not have been such that harm comes to her. Now consider the following case:

Ties: A train is on the path to kill an innocent stranger who is on the tracks through no fault of her own. Thankfully, the stranger can easily step aside and let the train go by. You, however, then tie her to the tracks, preventing her from escaping the path of the train. The stranger is killed.

Ties is a Denial of Escape Case. It also intuitively strikes us as doing harm: your action makes it the case that the victim is (and causes her to be) in the path of the train and is harmed when she otherwise would not have been. Furthermore, all else being equal, do we believe that your behavior was any less morally repugnant in Ties than in Push? Is tying her to the tracks any more permissibleor does it require any lesser justification-than pushing her onto the tracks? I think not. The morally relevant facts are identical: you did not initiate the train in motion, yet you act to interfere in the sequence of events to ensure that the stranger is in its path when she otherwise would not have been, such that harm will come to her. Tying the stranger to the tracks so that she is killed by the train is on a moral par as an equally pro tanto impermissible instance of doing harm as pushing her onto the track so that she is killed by the train.

One difference might be that in Ties you keep them in harm's way whereas in Push you put them in harm's way. Yet this does not appear to make any moral difference to the permissibility of your actions or their classification as either doing or allowing. If it were true that holding someone in harm's way is not an instance of doing harm and is thereby more permissible, whereas putting someone in harm's way is an instance of doing harm and thereby more impermissible, then it would be true that my holding your hand on a soon-to-be hot stove is not an instance of doing harm and is more permissible, compared to my pushing your hand onto a hot stove, which is an instance of doing harm and more impermissible. This seems bizarre. Both holding someone's hand on a hot stove and pushing someone's hand onto a hot stove are clearly acts of doing harm and require equally substantial justifications without which they are both equally morally impermissible. Therefore, the particular physical movements you use to ensure a 
person is in harm's way when she otherwise would not have been is not a morally salient fact and makes no moral difference to permissibility or to whether one counts as doing or allowing harm. There is no moral difference then between Ties and Push. Therefore, Denial of Escape constitutes doing harm.

It might now be objected that, though Ties is plausibly doing harm, this is not analogous to containment policies, since in Ties one directly physically interferes with the victim's body, whereas in containment policies this is not the case, since containment simply blocks their escape.

In response, in many cases containment policies do interfere with refugees' bodies as they are physically intercepted, apprehended, coerced, restrained, and forcibly returned to harmful conditions, thus denying their escape. In such cases, refugees are physically forced to stay in harm's way and not escape. Even if containment policies did not interfere with refugees' bodies, physical interference does not make a moral difference. We standardly accept in typical doing harm cases that physical interference with a person's body is not morally significant. If I set a train in motion down a track toward a stranger and it kills her, it does not matter that I did not myself physically interfere with the person's body. I can push a boulder down a hill, fire an arrow, or release the dogs without touching you. Physical interference or the particular mediating tool or method one uses does not make a moral difference to permissibility or to determining doing or allowing harm.

Alternatively, to show that physical interference is irrelevant, we can reimagine Ties:

Barrier: A train is on the path to kill an innocent stranger who is on the tracks through no fault of her own. The stranger can easily step aside and let the train go by. You decide to erect a barrier, preventing the stranger from stepping aside.

Or:

Bananas: A train is on the path to kill an innocent stranger who is on the tracks through no fault of her own. You throw down some banana skins so that every time the stranger desperately tries to escape she slips and falls back into the path of the train.

Are we to believe that your behavior was any more permissible in these cases or that by using a different method your action now counts as allowing harm? I think not. Bananas, bricks, or bondage, it makes no moral difference which mediating method or tool you use or whether you physically interfere with the victim's body or not. What is morally relevant is that an agent acts to interfere in 
a sequence of events to ensure that a victim is in harm's way when she otherwise would not have been and thus ensures a harm occurs to her that would not have occurred had the agent not acted. This is morally indistinguishable from Push in terms of pro tanto impermissibility and classification as doing harm. Therefore, Denial of Escape is doing harm.

Other Denial of Escape Cases will also intuitively strike us as doing harm. There is a fire in a building, you block the fire exit, and as a result people are burned who would have otherwise escaped. Someone is swimming underwater in a partially frozen lake, and you block the hole in the ice through which they could have otherwise escaped such that they drown. Someone is in a room threatened by an attacker and you shut and lock the door to confine them there, such that they are harmed when they otherwise could have escaped. What is worth emphasizing is that in each of these Denial of Escape Cases you perform an action that causes and makes it the case that persons are harmed when they would not have been had you not acted. These actions are clearly instances of doing harm and are also morally repugnant. Therefore Denial of Escape Cases are instances of doing harm. Containment policies are denials of escape. These policies are therefore harming refugees by confining them in harmful conditions they could have otherwise escaped. We are tying refugees to the tracks.

\section{DENIAL OF ESCAPE AND WOOLLARD'S DISTINCTION}

To supplement the above assessment of Denial of Escape Cases, let us apply Woollard's framework for determining doing and allowing harm. Her framework represents, to my knowledge, the most thorough and nuanced theoretical analysis of the distinction available in the literature. There are numerous steps to Woollard's framework. First, an agent's behavior will count as doing harm "if and only if a relevant fact about the agent's behavior is part of the sequence leading to harm." ${ }^{38}$ In contrast, an agent's behavior counts as merely allowing harm "if and only if a fact about the agent's behavior is relevant to but not part of the harmful sequence." ${ }^{39}$ In sum, the agent's behavior must be a part of the sequence leading to harm to count as doing harm.

Second, other things being equal, in order for an agent's behavior to be part of the sequence, it must be a substantial fact. Substantial facts are informative or noteworthy facts that tell us about the occurrence or presence of something: "it must tell us about some addition or change to the world." ${ }^{40}$ For example, the

38 Woollard, Doing and Allowing Harm, 23, 80.

39 Woollard, Doing and Allowing Harm, 23.

40 Woollard, Doing and Allowing Harm, 29. 
fact that a person pushed a boulder is a substantial fact, the fact that the boulder rolled down the hill is a substantial fact, and the fact that the boulder crushed a car is a substantial fact. Each are significant, informative facts about the occurrence or presence of something. These substantial facts are then each necessary parts of the sequence.

Non-substantial facts, on the other hand, simply tell us about the absence of something: that "something that could have prevented the sequence was absent." ${ }^{41}$ For example, the fact that a person or object did not block the boulder, or that the boulder did not disintegrate, are non-substantial facts. Other things being equal, non-substantial facts cannot be part of, but only relevant to, a sequence leading to harm. ${ }^{42}$ When we ignore the non-substantial facts the sequence will remain the same.

Last, in order to be a substantial fact, typically it must be a positive fact. Following Jonathan Bennett's distinction, Woollard suggests that a fact is positive about an object or behavior if and only if most of the ways the object or behavior could have been would not have made the corresponding proposition true. ${ }^{43} \mathrm{~A}$ fact is negative about an object or behavior if most of the ways it could have been would have made the corresponding proposition true. ${ }^{44}$ In more detail:

Positive facts tell us that something was the case: Bob pushed the boulder; the cat is on the roof. They give us a fairly definite piece of information, pinning us down to a small number of alternatives. In contrast, negative facts merely tell us that something was not the case: Bob did not interpose the car; the cat is not in the road. They do not tell us very much about how the world is, for they only rule out the relatively small set of alternatives corresponding to the positive proposition that has been negated. $^{45}$

In order to determine whether an agent's behavior was positive or negative, for

41 Woollard, Doing and Allowing Harm, 30.

42 For Woollard, there are some cases where a non-substantial fact can be part of a sequence, such as the removal of a barrier in safety-net cases that can be "a relatively substantial fact" when "(a) the barrier does not require the continued use of resources belonging to the agent and either (b) the barrier is owned by the victim or by a third party who has given, or would give, valid authorization for the victim to use the barrier or (c) the victim has a non-need based claim to the use of the barrier that is stronger than any non-need based claim the agent has to the barrier. In such cases, the removal of the barrier will count as doing harm" (Doing and Allowing Harm, 81).

43 Bennett, The Act Itself, 91-95.

44 Woollard, Doing and Allowing Harm, 44.

45 Woollard, Doing and Allowing Harm, 23. 
example, we consider all of the ways the agent could have moved: "if a fact about an agent's conduct is positive, this fact tells us that the agent moved in one of a relatively small number of ways." ${ }^{36}$ For example, the fact that Alice hit Brian with her fist is a positive fact since most of the ways Alice could have moved would not have made it the case that Brian was punched. Hitting Brian with her fist occupies a very small subset of potential positions that Alice could have occupied. In contrast, Carl's failing to block the punch is a negative fact since most of the ways Carl could have moved would also have failed to block the punch. Carl's failing to block the punch is part of a large subset of possible positions Carl could occupy.

If a fact about an object or behavior is positive (occupying a small subset of possible positions) then this is a substantial fact (noteworthy or significant). If a fact about an object or behavior is negative (occupying a large subset of possible positions), it is a non-substantial fact. "Positive facts are substantial, suitable to be part of a sequence leading to harm. Other things being equal, negative facts are non-substantial." ${ }^{47}$

In sum, on Woollard's account, paradigmatically an agent will count as doing harm if (1) a fact about his behavior is positive (occupying a small subset of possible positions) such that it is (2) a substantial fact (as the noteworthy presence, occurrence, or addition of something), which is then also (3) part of a sequence leading to harm. Let us now apply Woollard's framework to classify Denial of Escape cases.

First, the agent's placing (or introducing or creating) the obstacle to block an escape route is a positive fact since it is part of a small subset of possible behaviors. Most of the ways the agent could have acted would not have made it true that an obstacle was placed there. Colloquially speaking, they go "out of their way" to place the obstacle there. Second, the obstacle being placed there is then a substantial fact: it is informative and noteworthy as an occurrence, addition, or presence of something that was not the case before, rather than the absence of something. Third, this substantial fact is then also part of the sequence leading to harm as it is a necessary component of that sequence. Recall Ties and its variations. Consider the sequence without the placing of the obstacle to the escape route: There is a train heading down the track. A stranger is in the path of the train. The stranger steps aside. The train passes by. Now consider the sequence

46 Woollard, Doing and Allowing Harm, 41.

47 Woollard, Doing and Allowing Harm, 38. Also according to Woollard, in rare cases a negative fact can also be a substantial fact if and only if it is contrary to our normal presuppositionsfor example, if there was no oxygen in the air. However, this is not relevant for our purposes. For further explanation, see Woollard, Doing and Allowing Harm, 57. 
with the obstacle: There is a train heading down the track. A stranger is in the path of the train. An agent places an obstacle blocking the stranger from stepping aside. The train hits the stranger. Each of these statements is a positive and substantial fact that is a necessary part of a harmful sequence since if any one of the facts were not to obtain then the sequence would not be harmful. If we ignore the fact of the addition of the obstacle, the sequence would not be the same. Therefore, on Woollard's framework, the agent who places an obstacle blocking an escape from a harmful sequence meets each necessary desiderata and as such is connected to the sequence leading to harm in the relevant way to constitute doing harm.

Denial of Escape Cases, then, are instances of doing harm, and this is supported independently both by justified intuitive judgments and by a thorough theoretical analysis of the distinction between doing and allowing. Containment is a Denial of Escape Case. Containment is an instance of doing harm. Therefore, we are now in a position to confidently affirm that states that adopt containment policies are in fact harming refugees and as such are not innocent bystanders.

\section{NON-REFOULEMENT AND CONTAINMENT}

To close this paper, I wish to consider containment in the light of the principle of non-refoulement. Non-refoulement is the absolute legal and moral prohibition on returning a refugee from one's jurisdiction to territories where their life, freedom, or human rights would be threatened. ${ }^{48}$ It is accepted by all signatories to the Refugee Convention, is the most widely practiced norm among policy makers within the refugee regime, and is unanimously endorsed by all theorists (including those who argue for controlled borders). ${ }^{49}$ Violating non-refoulement does not cause the harmful conditions that endanger the lives, freedom, and human rights of refugees, but places refugees in these conditions. It would be ethically analogous to throwing an innocent child, who had escaped onto your dry land, back into the water where they may drown. It is widely agreed that such an act would be morally unthinkable. ${ }^{50}$

48 See unhCr, The 1951 Convention Relating to the Status of Refugees and Its 1967 Protocol, Article 33, "Prohibition of Expulsion or Return ('Refoulement')."

49 See Miller, Strangers in Our Midst, 78, 85; Walzer, Spheres of Justice, 60.

50 I thank an anonymous reviewer for pointing out that it is not uncontroversial to hold persons and states as morally analogous such that it is legitimate to apply principles of personal morality to state conduct. Nonetheless, I feel it is appropriate at least for the purposes of this paper. State policy is of course a legitimate target for ethical scrutiny. Further, states are agents with the capacity to act in ways similar to individual agents in the relevant sense that they have the capacity to act to harm, save, or fail to aid, and thus allow harm to others. As 
Now, consider containment that constitutes keeping refugees from one's jurisdiction in conditions where their life, liberty, and human rights would be under threat. Containment does not cause these harmful conditions but contains refugees there and prevents their escape. This is ethically analogous to holding an innocent child at arm's length in the water where they may drown, preventing them from swimming to safety onto your land.

Is it any more permissible to hold a child in the water where they may drown rather than throw a child into the water where they may drown? I think not. To do this to a child looking for safety I think we would also agree is morally unthinkable. There is no discernible moral difference between holding the child in the water and throwing the child into the water. We have seen in the comparison between Ties and Push that there is no moral difference between putting someone in harm's way and holding them in harm's way. The particular physical movements you use to ensure the child is in water when she otherwise would not have been are not morally relevant. Instead the morally salient facts are identical. Both holding the child in the water and throwing the child in the water are instances of doing harm. In both cases one performs an action that is a positive fact (holding the child or throwing the child). Both positive facts are substantial facts as they are informative and noteworthy occurrences and additions to the world. Both substantial facts are necessary parts of their respective sequences that lead to harm, since had each not obtained the child's life would not have been endangered: the thrown child would not have been placed in the dangerous conditions, and the held child would not have been confined to the dangerous conditions and could have escaped. Therefore, in both cases one acts to interfere with the sequence such that harm will come to the victim. There is no moral difference between these cases. Both are equally morally outrageous instances of doing harm.

Therefore, if refoulement is analogous to throwing the child back into the water and if containment is analogous to holding the child in the water, and if there is no moral difference between throwing the child in the water and holding the child in the water, then there is no moral difference between refoulement and containment. Refoulement and containment are equally impermissible instanc-

such, an application of the Doctrine of Doing and Allowing is transferable. Further, drawing parallels between individual and state obligations follows common practice in the literature on moral obligations to refugees since, as we have seen, most theorists invoke an analogy between an individual's obligation to save a person in need and a state's duty of rescue toward refugees. For two explicit examples, consider: "Like the bystander we [states] have an unambiguous duty of rescue towards them [refugees]" (Betts and Collier, Refuge, 99); and "There is a parallel here with the duty of rescue born by individuals in emergencies" (Miller, Strangers in Our Midst, 78). 
es of doing harm. Therefore, all states and theorists that unanimously recognize the outright moral prohibition against violating non-refoulement by placing refugees in conditions where their lives, freedom, and human rights would be under threat ought also to recognize the exact same moral prohibition against containment policies that confine refugees in conditions where their lives, freedom, and human rights would be under threat (all else equal). Under the letter of the law of the principle of non-refoulement, returning refugees is prohibited though containment is not. This "loophole," which has been seemingly exploited, makes a mockery of the principle of non-refoulement, and is ethically unsustainable. A potential significant policy implication of the above then is that reform is required such that containment is just as prohibited under international law as refoulement.

\section{THE MORAL PROHIBITION ON HARMING REFUGEES}

Border violence, forced detention, encampment, and containment are instances of doing harm to refugees. States that engage in such practices are not merely failing to fulfill urgent moral duties to help refugees in desperate need of aid, but are responding to their calls for aid by harming them. These states are not innocent bystanders. They are instead violating the stringent moral constraint against harming innocent persons. Therefore, the burden is on such states to provide a particularly substantial justification as to why it could possibly be morally acceptable to do so. Since doing harm requires a higher justification than failing to aid and allowing harm, economic and cultural considerations that might (for the sake of argument) make it permissible to fail to aid refugees will not be sufficient to pass the high threshold required to justify harming them. I believe that, given the extensive suffering and human rights violations endured by innocent refugees as a result of these practices, the requisite substantial justification will be difficult if not impossible to find. Such practices are likely to be morally indefensible.

As such I simply argue that in the absence of such a substantial justification it is morally impermissible for states to harm innocent refugees. Moreover, since these practices are direct harms, without justification these harmful practices will constitute a direct injustice against refugees. If this is true then, as I write this, states that adopt such practices are committing a serious and unconscionable injustice against some of the world's most vulnerable people who are seeking our help. Such states will then have urgent and compulsory duties to abolish such practices. Even if we have zero obligations to actively offer support, safety, and hope to refugees, at the very least we should refrain from willingly spending 
our time, effort, and resources in causing them undue, avoidable, and needless suffering. If we will not help refugees at the very least we should not harm them. This is not a sophisticated argument, but it has been overlooked, and its importance for the well-being of refugees is hard to overstate.

University of Reading b.hillier-smith@pgr.reading.ac.uk

\section{REFERENCES}

Amnesty International. "Croatia: EU Complicit in Violence and Abuse by Police against Refugees and Migrants," March 13, 2019. https://www.amnesty.org/ en/latest/news/2019/03/croatia-eu-complicit-in-violence-and-abuse-by -police-against-refugees-and-migrants.

BвC News. "Migrant Slavery in Libya: Nigerians Tell of Being Used as Slaves," January 2, 2018. https://www.bbc.com/news/world-africa-42492687.

Bennett, Jonathan. The Act Itself. Oxford: Clarendon Press, 1995.

Betts, Alexander, and Paul Collier. Refuge: Transforming a Broken Refugee System.

London: Penguin UK, 2017.

Carens, Joseph. The Ethics of Immigration. Oxford: Oxford University Press, 2013. Channel 4 News. "EU Immigration: Tortured for Trying to Enter Europe," February 25 , 2019. https://www.youtube.com/watch?v=CXzpfBGHUdg\&feature =youtu.be.

Chatty, Dawn. "The Syrian Humanitarian Disaster: Understanding Perceptions and Aspirations in Jordan, Lebanon and Turkey." Global Policy 8, no. s1 (February 2017): 25-32.

Dagger, Richard. "Politics, Rights, and the Refugee Problem." In War and Border Crossings: Ethics When Cultures Clash, edited by Peter A. French and Jason A. Short, 185-95. Oxford: Rowman and Littlefield, 2005.

Dearden, Lizzie. "Hungarian Border Guards 'Taking Selfies with Beaten Migrants.” The Independent, March 4, 2017. http://www.independent.co.uk/ news/world/europe/refugee-crisis-hungary-border-police-guards-fence -beating-asylum-seekers-migrants-serbia-push-back-a7610411.html.

Dutton, James. "For Refugees in Calais, Police Brutality Is a Daily Occurrence." The Independent, December 10, 2018. https://www.independent.co.uk/news/ long_reads/refugees-calais-jungle-camp-french-police-brutality-a 8674596 . html.

Frowe, Helen. Defensive Killing. Oxford University Press, 2014. 
Gardner, Molly. "A Harm-Based Solution to the Non-Identity Problem." Ergo 2, no. 17 (2015): 427-44.

Gibney, Matthew J. The Ethics and Politics of Asylum: Liberal Democracy and the Response to Refugees. Cambridge: Cambridge University Press, 2004.

Hanser, Matthew. "Harm." International Encyclopedia of Ethics, edited by Hugh LaFollette, February 1, 2013. https://doi.org/10.1002/9781444367072.wbiee186.

Hayden, Sally. "Somali Returned to Libya under Italian Policy Sets Himself on Fire." Irish Times, October 25, 2018. https://www.irishtimes.com/news/ world/africa/somali-returned-to-libya-under-italian-policy-sets-himself -on-fire-1.3675942.

Hillier-Smith, Bradley. "The Situation on the English Channel Is Indeed a 'Major Incident'-but It's the UK Government Who's at Fault, Not the Migrants." The Independent, December 29, 2018. https://www.independent. co.uk/voices/migrants-refugees-latest-english-channel-major-incident-sajid-javid-a8703551.html.

Human Rights Watch. "France: Calais Migrants at Risk as Cold Arrives," December 18, 2017. https://www.hrw.org/news/2017/12/18/france-calais-migrants -risk-cold-arrives.

—. "Like Living in Hell': Police Abuses Against Child and Adult Migrants in Calais," July 26, 2017. https://www.hrw.org/report/2017/07/26/ living-hell/police-abuses-against-child-and-adult-migrants-calais.

. "Q\&A: Why the EU-Turkey Migration Deal Is No Blueprint," November 14, 2016. https://www.hrw.org/news/2016/11/14/qa-why-eu-turkey-migration -deal-no-blueprint.

- "Towards an Effective and Principled Eu Migration Policy: Recommendations for Reform," June 18, 2018. https://www.hrw.org/news/2018/o6/18/ towards-effective-and-principled-eu-migration-policy.

—. "Why Greece Should \#OpenTheIslands," March 19, 2018. https://www. hrw.org/news/2018/03/19/why-greece-should-opentheislands.

—. "World Report 2018: Rights Trends in European Union," January 5, 2018. https://www.hrw.org/world-report/2018/country-chapters/european -union.

International Rescue Committee. “Unprotected, Unsupported, Uncertain," September 25, 2018. https://www.rescue.org/report/unprotected-unsupported -uncertain.

L'Auberge des Migrants. Calais: Police Harassment of Volunteers. August 2018. https://y9w4d3a4.stackpathcdn.com/wp-content/uploads/2018/o8/Police -Harrassment-of-Volunteers-in-Calais-1.pdf. 
McMahan, Jeff. "Killing, Letting Die, and Withdrawing Aid." Ethics 103, no. 2 (January 1993): 250-79.

Miller, David. Strangers in Our Midst. Cambridge, MA: Harvard University Press, 2016.

Parekh, Serena. Refugees and the Ethics of Forced Displacement. New York: Routledge, 2016.

Purves, Duncan. "Harming as Making Worse Off." Philosophical Studies 176, no. 10 (October 2019): 2629-56.

Quine, Oscar. "Calais Jungle Refugees Have Sewn Their Mouths Shut in Protest at the Camp Clearance." The Independent, March 4, 2016. http://www. independent.co.uk/news/world/europe/calais-jungle-refugees-sewmouths-shut-in-protest-at-camp-clearance-a6912806.html.

Rachels, James. "Active and Passive Euthanasia." In Bioethics: An Introduction to the History, Methods, and Practice, edited by Nancy S. Jecker, Albert R. Jonsen, and Robert A. Pearlman, 77-82. Sudbury, MA: Jones and Bartlett, 1997.

Rickless, Samuel C. "The Moral Status of Enabling Harm." Pacific Philosophical Quarterly 92, no. 1 (March 2011): 66-86.

Save the Children International. "Hundreds of Children Report Police Violence at EU Borders," December 24, 2018. https://www.savethechildren.net/news/ hundreds-children-report-police-violence-eu-borders.

Shacknove, Andrew E. “Who Is a Refugee?” Ethics 95, no. 2 (January 1985): 274-84

Souter, James. "Towards a Theory of Asylum as Reparation for Past Injustice." Political Studies 62, no. 2 (June 2014): 326-42.

Taylor, Diane. "Libya: Child Refugees Abused in uk-Funded Detention Centres." The Guardian, November 20, 2018. https://www.theguardian.com/ world/2018/nov/20/child-refugees-facing-abuse-in-libyan-detention -centres.

Tondo, Lorenzo. “'We Have Found Hell': Drawings Reveal Children's Trauma at Lesbos Camp." The Guardian, October 3, 2018. https://www.theguardian. com/global-development/2018/oct/o3/trauma-runs-deep-for-children-at -dire-lesbos-camp-moria.

Walzer, Michael. Spheres of Justice: A Defense of Pluralism and Justice. New York: Basic Books, 1983.

Woollard, Fiona. Doing and Allowing Harm. Oxford: Oxford University Press, 2015.

United Nations High Commissioner for Refugees (UNHCR). Convention and Protocol Relating to the Status of Refugees. December 2010. http://www.unhcr. 
$\mathrm{org} /$ protection/basic/3b66 c2aa1o/convention-protocol-relating-status -refugees.html.

- "Figures at a Glance," June 19, 2019. https://www.unhcr.org/figures-at -a-glance.html.

- Global Trends: Forced Displacement in 2016. June 19, 2017. http:// www.unhcr.org/statistics/unhcrstats/5943e8a34/global-trends-forced -displacement-2016.html.

- The 1951 Convention Relating to the Status of Refugees and Its 1967 Protocol. September 2011. https://www.unhcr.org/about-us/background/4ec262df9/ 1951-convention-relating-status-refugees-its-1967-protocol.html.

. "North Africa." http://reporting.unhcr.org/node/34.

- "UNHCR Study Shows Rapid Deterioration in Living Conditions of Syrian Refugees in Jordan," January 14, 2015. http://www.unhcr.org/news/ press/2015/1/54b635b49/unhcr-study-shows-rapid-deterioration-living -conditions-syrian-refugees.html.

United Nations (UN) News Service Section. "Conditions of Syrian Refugees in Lebanon Worsen Considerably, un Reports," December 23, 2015. http:// www.un.org/apps/news/story.asp?newsid=52893\#.wyshpnpytsm. 